\title{
Sex and depression in the National Comorbidity Survey. II: Cohort effects
}

\author{
Ronald C. Kessler a,b,*, Katherine A. McGonagle a , Christopher B. Nelson a , \\ Michael Hughes ${ }^{\mathrm{a}, \mathrm{c}}$, Marvin Swartz ${ }^{\mathrm{d}}$ and Dan G. Blazer ${ }^{\mathrm{d}}$ \\ a Institute for Social Research and ${ }^{b}$ Department of Sociology, The University of Michigan, Ann Arbor, MI, USA, ${ }^{c}$ Virginia Polytechnic \\ Institute and State University, and ${ }^{d}$ Department of Psychiatry, Duke University Medical Center, Durham, NC, USA
}

(Received 30 June 1993)

(Revision received 6 July 1993)

(Accepted 28 July 1993)

\section{Summary}

Data from a nationally representative sample of the general population are used to study cohort differences in the prevalence of DSM-III-R Major Depressive Episode (MDE). We document increasing lifetime prevalence of MDE among both men and women in more recent cohorts, but no major change in the sex ratio over the 40-year period retrospectively covered in the survey. We find a cohort difference in 12-month MDE, with older women much more likely than older men to have recurrent episodes. This sex difference in recurrence plays an important part in the elevated 12-month prevalence of depression among women compared to men in the $45-54$ age range.

Key words: Major depressive episode; Affective disorder; Epidemiologic studies; Sex differences; Diagnostic category; Cohort effects

As documented in a number of recent reviews (Bebbington, 1988; Nolen-Hoeksema, 1987; Weissman and Klerman, 1992; Weissman et al., in press), epidemiologic studies consistently find that women are more likely than men to have

\footnotetext{
* Corresponding author. Institute of Social Research, Box 1248, The University of Michigan, Ann Arbor, MI 4812061248, USA. Tel.: (313) 936-0550; Fax: (313) 763-3750.

Presented at the NIMH Workshop, Towards a New Psychobiology of Depression in Women, September 18, 1992.
}

major depression. In an earlier paper in this issue (Kessler et al., in press), we presented data on sex and depression from the National Comorbidity Survey (NCS; Kessler et al., submitted), the first survey in the U.S. to administer a structured psychiatric interview to a nationally representative sample of the general population. Consistent with previous research, we found that women were approximately 1.7 times as likely as men to report a lifetime history of DSM-III-R Major Depressive Episode (MDE; American Psychiatric Association, 1987). We also found that the sex 
difference in risk of first onset initially emerged in the age range 10-14 and persisted through the 50-54-year age range. Moreover, women were 1.7 times as likely as men to report 12-month MDE. However, there was no aggregate sex difference in either 12-month chronicity or 12-month acute recurrence of depression, suggesting that the higher prevalence of 12-month depression among women is largely due to women having a higher lifetime risk of first onset than men.

These aggregate results have potentially important implications. The finding that women have a higher risk than men of becoming depressed but not of staying depressed discredits the argument of some sex role theorists that the higher prevalence of depression among women than men is due to the fact that female role-related strains create more chronic depression (e.g., Barnett and Baruch, 1987; Gove and Geerken, 1977). Our results also indirectly argue against the claim that the sex difference in depression will disappear if the adult sex roles of men and women are made more equal (e.g., Jenkins, 1985; Wilhelm and Parker, 1989). The finding that the sex difference in onset risk begins in early adolescence coupled with the finding from the Epidemiologic Catchment Area (ECA) Study that it ends in the mid-50s (Burke et al., 1990) is consistent with theories that implicate the menstrual cycle in the higher risk of depression among women (e.g., Janowsky and Rausch, 1985; Rubinow et al., 1986).

However, a limitation of our earlier report is that the results were based on data aggregated across birth cohort. This is an important limitation because of evidence for increasing rates of depression in more recent cohorts both in the U.S. (Lewinsohn et al., 1993; Weissman et al., 1991) and in other parts of the world (Cross-National Collaborative Group, 1992; Hagnell et al., 1982; Weissman et al., in press). Substantial cohort differences in our basic results would argue against a biological interpretation because there is no reason to believe that sex differences in biology have changed dramatically over the period of a few decades. Furthermore, if a cohort effect could be documented, an investigation of whether the sex difference appears in only some cohorts, is more pronounced in some cohorts, or emerges at different ages in different cohorts could provide important clues for further investigation of causal mechanisms. We report the results of such an investigation in the present paper.

In addition to following the lead of Weissman and her colleagues (in press) in examining cohort differences in cumulative onset risk for MDE separately by sex, we consider two other cohortrelated issues. First, we examine the possibility that there has been a decreasing sex difference in depression in more recent cohorts. The impetus for this investigation is the fact that the female/ male cumulative risk ratio of lifetime MDE in the NCS (1.7) is considerably lower than in the ECA (2.4; Weissman et al., 1991) and the suspicion that this may be due to a cohort effect. Consistent with this suspicion, several long-term longitudinal studies have documented a decreasing sex difference in global measures of distress (Kessler and McRae, 1981; Murphy et al., 1986; Srole and Fischer, 1980) and Weissman et al. (in press) has documented that rates of major depression in birth cohorts born since World War II are rising in males and stabilizing in females across four countries (Australia, Canada, New Zealand, and the United States). Second, we study cohort differences in the relationship between sex and 12month prevalence of MDE. The rationale for this analysis is based on the finding from our earlier report that the female/male risk ratio of 12 month prevalence is fairly similar across cohorts. We did not investigate whether the determinants of this ratio were the same, but did detect some evidence for an increasing sex difference in recurrence risk in our oldest cohort. This difference as well as other cohort differences in the determinants of 12-month prevalence are considered more formally in the present report.

\section{Methods}

\section{Sample}

The data come from the National Comorbidity Survey (NCS; Kessler et al., submitted), a Congressionally mandated study of psychiatric disorders in the U.S. designed to produce data on the prevalence, risk factors, and consequences of psychiatric morbidity and comorbidity. The NCS is 
the first nationally representative general population survey of the U.S. to administer a structured psychiatric interview and the first large-scale psychiatric epidemiologic survey in the U.S. to use DSM-III-R diagnostic criteria. The NCS interviewed a nationally representative sample of 8098 respondents in the age range 15-54 between September 14, 1990 and February 6, 1992. The sampling frame was the noninstitutionalized household population plus students living in campus group housing. Interviews were administered by the professional field staff of the Survey Research Center (SRC) at the University of Michigan. Interviewers were carefully trained and closely monitored throughout the field period. The response rate was $82.4 \%$. More details about the design of the NCS are presented elsewhere (Kessler et al., submitted; Kessler et al., in press).

\section{Diagnostic assessment}

DSM-III-R diagnoses of Major Depressive Episode (MDE) are based on a modified version of the Composite International Diagnostic Interview (CIDI; World Health Organization, 1990), a structured diagnostic interview designed to be used by interviewers who do not have clinical training. As described more fully elsewhere (Kessler et al., in press), the CIDI was modified for the NCS to include the stem questions for MDE and a number of other disorders in a Life Review Section designed to facilitate active memory search for lifetime episodes. The Life Review Section was administered prior to probing any positive stem responses in an effort to avoid conscious nondisclosure of stem questions once respondents recognized that positive stem responses lead to further questioning. Blind clinical reinterviews in a random subsample of NCS respondents using the Structured Clinical Interview for DSM-III-R Diagnosis (SCID; Spitzer et al., 1992) as the validation standard yielded a positive predictive value of $0.70( \pm 0.10)$ and a negative predictive value of $0.96( \pm 0.06)$ for the NCS/ CIDI DSM-III-R diagnosis of lifetime MDE. These results compare favorably with those obtained in previous general population validation studies of MDE in structured diagnostic interviews (Anthony et al., 1985; Helzer et al., 1985; Robins et al., 1981).

\section{Analysis procedures}

Only one randomly selected respondent was interviewed in each predesignated NCS sample household. This means that within-household probabilities of selection are inversely proportional to the number of eligible persons in the household. The final NCS data were weighted to adjust for this between-household variation in probability of selection as well as for response bias and discrepancies between the final sample and the total U.S. population on a variety of sociodemographic variables. Appropriate standard errors for these weighted data were obtained by using the Taylor series linearization method (Woodruff and Causey, 1976) for the standard errors of proportions and the method of Balanced Repeated Replication (Kish and Frankel, 1970) for the standard errors of logistic regression coefficients (Hosmer and Lemeshow, 1989) and discrete-time hazard coefficients (Allison, 1984). A more detailed discussion of these internal resampling methods is presented in Kessler et al. (in press).

\section{Results}

\section{Cohort differences in cumulative lifetime risk}

Cohort-specific cumulative hazards of lifetime MDE are shown graphically in Fig. 1a (males) and $b$ (females) as well as in Table 1 for each of the four 10-year birth cohorts represented in the NCS. There is a consistent trend for lifetime risk to be higher at all ages in successively younger cohorts. It is noteworthy that this cohort difference is much more pronounced in the youngest cohort for both men and women. This can be seen most clearly by comparing lifetime risks within age across cohorts in Table 1. A formal comparison is presented in Table 2. Sex-specific risk ratios up through age 24 , which is the oldest age where comparisons can be made across all four cohorts, average 2.37 in the youngest (196675) compared to the second youngest cohort (1956-65), 1.68 in the second youngest compared to the third cohort (1946-55), and 1.43 in the third compared to the fourth cohort (1936-45).

The general shape of this cohort effect is similar to the effect found in the ECA study (Weissman et al., 1991). However, as noted above, the 


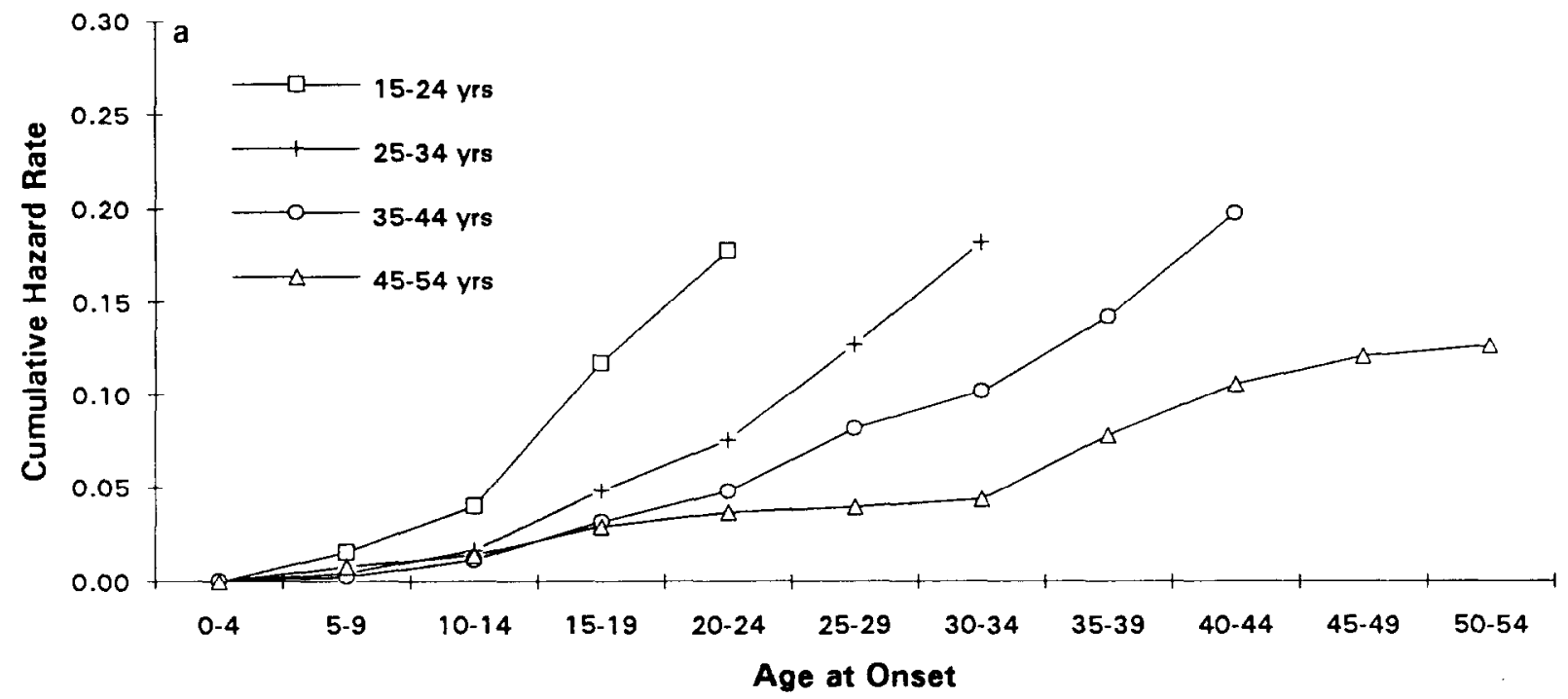

Figure 1a. Cohort differences in the cumulative age of onset of MDE-males.

largest inter-cohort difference in the NCS is for the youngest cohort (ages 15-24) versus the three older cohorts (ages 25-54). Respondents in the youngest NCS cohort were only between 5 and 15 years of age at the time the ECA study was carried out. Therefore, in finding a substantial increase in risk of depression in this youngest cohort we are documenting an extension of the cohort effect found in the ECA.
Inter-cohort differences in the relationship between sex and lifetime risk

There is an inter-cohort difference in the age at which the sex difference in MDE first emerges in the NCS. This is seen in Table 3, where we report cohort-specific cumulative relative hazards (female/male) of first onset by 5-year age intervals. The elevated female cumulative hazard can be observed by age 14 in the youngest cohort and

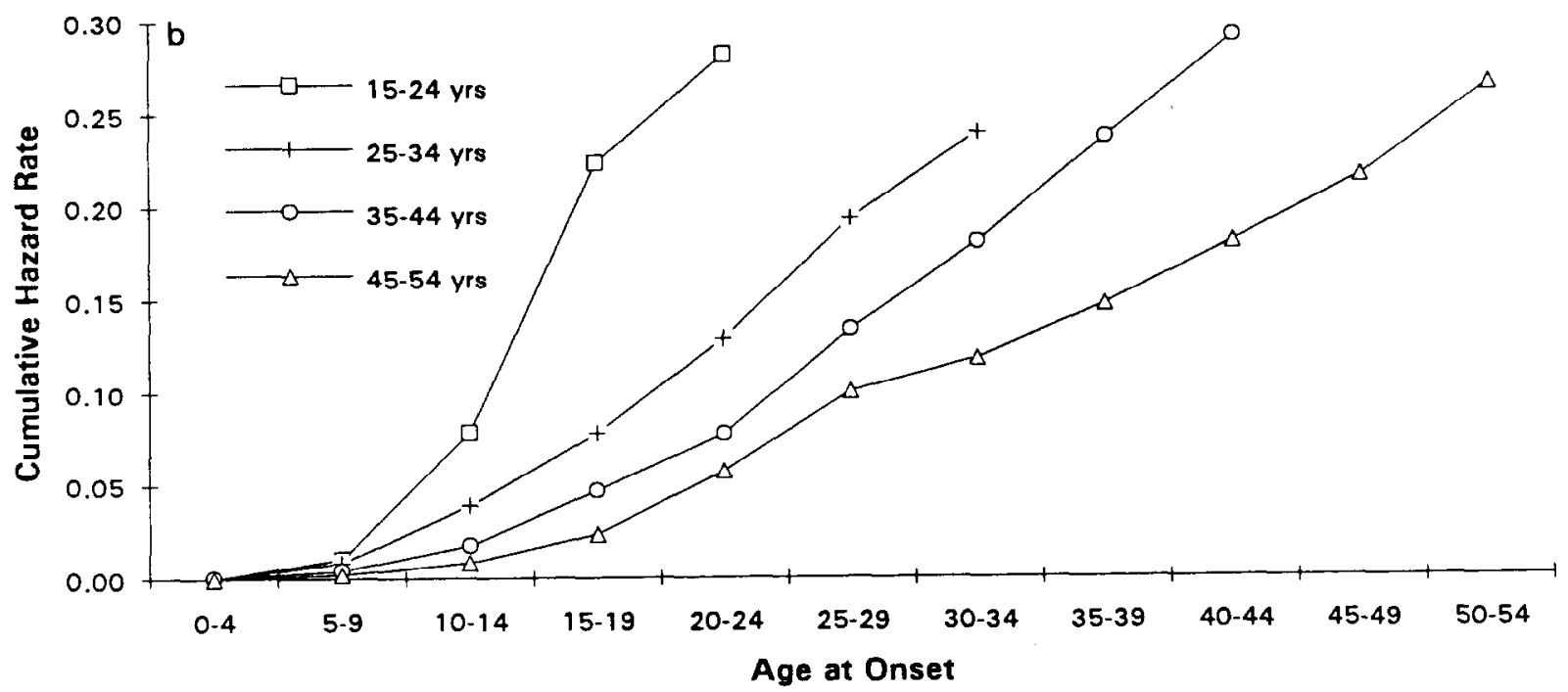

Figure 1b. Cohort differences in the cumulative age of onset of MDE-females. 
TABLE 1

Cohort-specific lifetime prevalence of MDE separately for males and females

\begin{tabular}{|c|c|c|c|c|c|c|c|c|}
\hline \multirow[t]{3}{*}{ Age } & \multicolumn{8}{|l|}{ Cohort } \\
\hline & \multicolumn{2}{|c|}{$1966-1975$} & \multicolumn{2}{|c|}{$1956-1965$} & \multicolumn{2}{|c|}{$1946-1955$} & \multicolumn{2}{|c|}{$1936-1945$} \\
\hline & $\overline{\mathrm{M}}$ & $F$ & $\overline{\mathrm{M}}$ & $F$ & $\overline{\mathrm{M}}$ & $\mathrm{F}$ & $\overline{\mathrm{M}}$ & $\mathrm{F}$ \\
\hline $5-9$ & 0.016 & 0.011 & 0.005 & 0.009 & 0.003 & 0.004 & 0.008 & 0.002 \\
\hline $10-14$ & 0.040 & $0.078^{*}$ & 0.017 & $0.039^{*}$ & 0.012 & 0.018 & 0.014 & 0.009 \\
\hline $15-19$ & $0.117 *$ & 0.224 * & 0.048 & $0.078 *$ & 0.031 & 0.047 & 0.029 & 0.024 \\
\hline $20-24$ & $0.178 *$ & $0.281 *$ & $0.076 *$ & $0.129 *$ & 0.048 & 0.077 & 0.037 & 0.057 \\
\hline $25-29$ & - & - & $0.127^{*}$ & $0.193 *$ & $0.082 *$ & 0.134 & 0.039 & 0.100 \\
\hline $30-34$ & - & - & $0.182 *$ & $0.239 *$ & $0.102 *$ & $0.181 *$ & 0.044 & 0.118 \\
\hline $35-39$ & - & - & - & - & $0.142 *$ & $0.237 *$ & 0.078 & 0.147 \\
\hline $40-44$ & - & - & - & - & $0.198 *$ & $0.291 *$ & 0.106 & 0.181 \\
\hline $45-49$ & - & - & - & - & - & - & 0.121 & 0.216 \\
\hline $50-54$ & - & - & - & - & - & - & 0.127 & 0.266 \\
\hline
\end{tabular}

* Significantly different from the prevalence in the 1936-1945 cohort at the 0.05 level (two-tailed test).

by age 9 in the next two older cohorts, but not until age 24 in the oldest cohort. This much later emergence of the sex difference in the oldest cohort could be due to a true cohort effect or to less accurate recall of early-onset depression in the oldest cohort. As noted earlier, we would not expect this cohort effect to exist if biological factors associated. with puberty play a part in causing the emergence of the sex difference in depression during adolescence. Therefore, if this cohort effect is genuine and not a result of recall bias, then it must be due to environmental, rather than biological, risk factors.

Despite this cohort difference in the age at which the sex difference in MDE first emerges, the hazard rate ratio does not differ greatly across cohorts by age 24 , the oldest age where we can compare the four cohorts. The ratio is 1.90 in the youngest cohort and decreases monotonically to 1.57 in the oldest cohort, a difference which is not statistically significant in this sample. There is a trend for the rate ratios at ages older than 24 to be larger in successively older cohorts, suggesting that the sex difference in the onset of MDE during the middle years of life has become smaller in younger cohorts. However, only one of the 14 possible pairwise inter-cohort comparisons in Table 3 beginning at age 24 is statistically significant - the difference between the 1.54 rate ratio at age 34 in the 1956-65 cohort and the 2.79 rate ratio at the same age in the 1936-45 cohort $(l=2.2, P<0.05)$. The general similarity of the

TABLE 2

Sex-specific inter-cohort cumulative rate ratios for lifetime MDE

\begin{tabular}{|c|c|c|c|c|c|c|}
\hline \multirow[t]{3}{*}{ Age } & \multicolumn{6}{|c|}{ Cohort } \\
\hline & \multicolumn{2}{|c|}{$1966-75 / 1956-65$} & \multicolumn{2}{|c|}{$1956-65 / 1946-55$} & \multicolumn{2}{|c|}{$1946-55 / 1936-45$} \\
\hline & $\mathrm{M}$ & $\mathrm{F}$ & $\mathbf{M}$ & $\mathbf{F}$ & $\mathrm{M}$ & $\mathrm{F}$ \\
\hline $5-9$ & 3.20 & 1.22 & 1.67 & 2.25 & 0.38 & 2.00 \\
\hline $10-14$ & 2.35 & 2.00 & 1.42 & 2.17 & 0.86 & 2.00 \\
\hline $15-19$ & 2.44 & 2.87 & 1.55 & 1.66 & 1.07 & 1.96 \\
\hline $20-24$ & 2.34 & 2.18 & 1.58 & 1.68 & 1.30 & 1.35 \\
\hline $25-29$ & - & - & 1.55 & 1.44 & 2.10 & 1.34 \\
\hline $30-34$ & - & - & 1.78 & 1.32 & 2.32 & 1.53 \\
\hline $35-39$ & - & - & - & - & 1.82 & 1.61 \\
\hline $40-44$ & - & - & - & - & 1.87 & 1.61 \\
\hline
\end{tabular}


risk ratios across cohorts beginning at age 24 is much more impressive than this one significant difference, with the average of the ratios equal to 1.76 and the range between 1.54 and 2.79. This similarity across cohorts is particularly striking in light of the finding in Table 1 that there is a roughly 5 -fold increase in the lifetime prevalence of MDE across these cohorts.

The relative importance of incidence, chronicity and recurrence

As noted earlier, females are approximately 1.7 times as likely as males to report a 12-month episode and this sex ratio of 12-month prevalence is fairly constant across cohorts in the NCS. However, our earlier analysis suggested that the causes of this consistent pattern may differ by cohort. In particular, we found that females in the oldest NCS cohort had a higher recurrence risk than their male counterparts. This result is consistent with a finding from a 1-year prospective analysis of the course of depression in the ECA study which found that older women were more likely than other respondents to remain depressed 1 year after the baseline assessment (Sargeant et al., 1990). The ECA investigators speculated that this higher recurrence risk might play an important part in explaining the continuing existence of a sex difference in depression among older re- spondents, but were not able to investigate the extent to which this was true.

In order to explore this issue more fully, we considered three factors that contribute to 12 month prevalence: the risk of first onset in the period, the risk of chronic depression in the period among respondents with a prior history, and the risk of episode recurrence in the period among respondents with a prior history who are not chronically depressed. Chronic depression was defined for purposes of this analysis as either a single lifetime episode that was still active at the time of interview or current depression among persons with a history of multiple episodes that had never been separated by several months or more of normal functioning. Recurrent depression was defined as an acute onset of a new episode of depression in the 12-month period prior to the NCS interview among the subsample of respondents with a lifetime history who were not chronically depressed.

Using these definitions, we expressed sexspecific 12-month prevalence $(P)$ as a sum of these components as follows:

$P=R_{1} \times(1-\mathrm{PH})+R_{2} \times \mathrm{PH}+R_{3} \times \mathrm{PH}$,

where $\mathrm{PH}$ is the proportion of the sample who had a prior history of depression as of 12 months

TABLE 3

Cumulative female/male rate ratios for lifetime MDE

\begin{tabular}{|c|c|c|c|c|c|c|c|c|}
\hline \multirow[t]{3}{*}{ Age } & \multicolumn{8}{|l|}{ Cohort } \\
\hline & \multicolumn{2}{|c|}{ 1966-1975 } & \multicolumn{2}{|c|}{$1956-1965$} & \multicolumn{2}{|c|}{$1946-1955$} & \multicolumn{2}{|c|}{$1936-1945$} \\
\hline & OR & $(95 \% \mathrm{Cl})$ & OR & $(95 \% \mathrm{Cl})$ & OR & $(95 \%)$ & OR & $(95 \% \mathrm{Cl})$ \\
\hline 9 & 0.68 & $(0.24,1.90)$ & 1.86 & $(0.44,7.93)$ & 1.73 & $* *$ & 0.25 & $* *$ \\
\hline 14 & $2.00^{*}$ & $(1.05,3.79)$ & $2.39 *$ & $(1.32,4.32)$ & 1.54 & $(0.75,3.15)$ & 0.62 & $(0.14,2.83)$ \\
\hline 19 & $2.03 *$ & $(1.31,3.16)$ & $1.65 *$ & $(1.18,2.31)$ & 1.52 & $(0.90,2.57)$ & 0.81 & $(0.30,2.17)$ \\
\hline 24 & $1.90^{*}$ & $(1.26,2.86)$ & $1.77 *$ & $(1.39,2.26)$ & $1.65^{*}$ & $(1.12,2.43)$ & 1.57 & $(0.74,3.35)$ \\
\hline 29 & & & $1.62 *$ & $(1.26,2.07)$ & $1.70 *$ & $(1.20,2.40)$ & $2.59 *$ & $(1.50,4.48)$ \\
\hline 34 & & & $1.54 *$ & $(1.20,1.98)$ & $1.86^{*}$ & $(1.39,2.49)$ & $2.79 *$ & $(1.72,4.53)$ \\
\hline 39 & & & & & $1.78 *$ & $(1.39,2.30)$ & $1.97 *$ & $(1.29,3.02)$ \\
\hline 44 & & & & & $1.73 *$ & $(1.35,2.22)$ & $1.80^{*}$ & $(1.19,2.71)$ \\
\hline 49 & & & & & & & $1.87 *$ & $(1.24,2.84)$ \\
\hline 54 & & & & & & & $1.96 *$ & $(1.29,2.97)$ \\
\hline
\end{tabular}

* Significant at the 0.05 level (two-tailed test).

** Low precision. 
TABLE 1

The effects of first onset, chronicity, and recurrence on 12 month prevalence of MDE, separately for males and females *

\begin{tabular}{lllllll}
\hline \multicolumn{1}{c}{$P$} & $(1-\mathrm{PH})$ & $R_{\mathrm{I}}$ & $\mathrm{PH}$ & $R_{2}$ & $R_{3}$ \\
\hline A. Male & & & & & & \\
$15-24$ & 0.095 & 0.912 & 0.024 & 0.088 & 0.391 & 0.435 \\
$25-34$ & 0.079 & 0.887 & 0.019 & 0.113 & 0.270 & 0.278 \\
$35-44$ & 0.080 & 0.865 & 0.104 & 0.135 & 0.228 & 0.282 \\
$45-54$ & 0.039 & 0.888 & 0.006 & 0.112 & 0.190 & 0.107 \\
Total & 0.077 & 0.887 & 0.017 & 0.112 & 0.268 & 0.281 \\
B. Female & & & & & & \\
$15-24$ & 0.163 & 0.829 & 0.044 & 0.171 & 0.390 & 0.348 \\
$25-34$ & 0.116 & 0.831 & 0.031 & 0.169 & 0.237 & 0.299 \\
$35-44$ & 0.127 & 0.782 & 0.025 & 0.218 & 0.152 & 0.342 \\
$45-54$ & 0.111 & 0.796 & 0.017 & 0.204 & 0.163 & 0.313 \\
Total & 0.129 & 0.811 & 0.030 & 0.189 & 0.228 & 0.324 \\
\hline
\end{tabular}

* $P, 12$-month prevalence of $\mathrm{MDE} ; R_{1}$, the risk that a respondent with no prior history had a first onset in the 12 months before the interview; (1-PH), the proportion of the sample who did not have a prior history of depression as of 12 months before the interview; $R_{2}$, the risk that a respondent with a prior history was chronically depressed in the 12 months before the intcrvicw; $\mathrm{PH}$, the proportion of the sample who had a prior history of depression as of 12 months before the interview; $R_{3}$, the risk that a respondent with a prior history had an acute recurrence in the 12 months before the interview.

before the interview; $(1-\mathrm{PH})$ the proportion of the sample who did not have a prior history; $R_{1}$ the risk that a respondent with no prior history had a first onset in the 12 months before the interview; $R_{2}$ the risk that a respondent with a prior history was chronically depressed in the 12 months before the interview, and $R_{3}$ the risk that a respondent with a prior history had an acute recurrence in the 12 months before the interview. The product $R_{1} \times(1-\mathrm{PH})$ is the proportion of the sample with 12-month incident depression. The product $R_{2} \times \mathrm{PH}$ is the proportion with 12 month chronic depression. The product $R_{3} \times \mathrm{PH}$ is the proportion with 12 -month recurrent depression.

The parameter values for Eqn. 1 are reported in Table 4 separately for men and women in each of the four 10-year NCS birth cohorts. Several results are noteworthy. First, the risk of first onset $\left(R_{1}\right)$ decreases in successively older cohorts among both men and women. 'This result is consistent with age of onset analyses in both the
ECA (Burke et al., 1990) and the NCS (Kessler et al., in press) samples which show that onset risk for MDE is greatest during the teenage years and early $20 \mathrm{~s}$ and declines steadily at later ages. Second, the value of $R_{1}$ in each cohort is larger for women than men, consistent with our earlier finding that women have a greater risk of first onset than men throughout the agc range covered by the NCS. Third, the value of $R_{2}$ is larger for men than women across all cohorts. This means that men with a history of depression are more likely than women with a history of depression to become chronically depressed. However, this is counterbalanced by a fourth observation, that the value of $\mathrm{PH}$ in each cohort is considcrably lower for men than women; that is, there are many fewer men than women with a history of depression. Fifth, the value of $R_{3}$ in all but the youngest cohort is greater for women than men. This means that among those with a history of depression, women are more likely than men to have 12 month recurrent episodes.

It is possible to formalize these comparisons by using demographic rate decomposition, an algebraic technique for decomposing differences in prevalences (in this case, between men and women) as a function of differences in parameter values for component processes. The logic of the technique is to sequentially substitute values $R$, $\mathrm{PH}$ and $(1-\mathrm{PH})$ of one sex for the comparable values of the other sex in the same cohort and recalculate the equation to determine the effect on the period prevalence of the first sex. For example, we could substitute 0.044 (the value of $R_{1}$ for females in the youngest cohort) for the value of $R_{1}$ in the male equation in the youngest cohort and show that the 12-month prevalence of MDE among men in this cohort would increase to 0.113 (rather than the observed value of 0.095 ) if the onset risk of men was as great as the onset risk of women. If this happened, the observed sex difference in 12-month prevalence would be reduced from $0.068(0.163-0.095)$ to $0.050(0.163$ -0.113 ). By continuing this substitution process for the values of $R_{2}, R_{3}, \mathrm{PH}$ and $(1-\mathrm{PH})$ it is possible to decompose the total observed sex difference in 12-month prevalence into unique components due to sex differences in: (a) risk of first onset, (b) risk of chronicity, (c) risk of recur- 
rence, and (d) the indirect effect of first onset through prior history. A more formal discussion of this decomposition technique can be found in Iams and Thornton (1975) and Winsborough and Dickinson (1971).

The results of applying this technique to the data in Table 4 are presented in Table 5. The totals in this table are the female-male differences in 12-month prevalence. The other rows show the components that comprise these totals. The results in the first row show that the greater female risk of first onset throughout the age range of the sample causes a fairly constant elevation of the sex difference in 12-month prevalence averaging 0.010 and ranging between 0.008 and 0.014 across cohorts. This differential incidence component is equal to between $11 \%$ and $24 \%$ of the observed sex difference in 12-month prevalence across cohorts. The results in the second row show that the indirect effect of first onset through prior history causes an increase in the sex difference averaging 0.042 and ranging between 0.030 and 0.066 with no apparent trend across cohorts other than that this component is considerably more pronounced in the youngest cohort than the older cohorts. This component explains between $81 \%$ and $96 \%$ of the observed sex difference in 12-month prevalence in the three youngest cohorts and $49 \%$ in the oldest cohort. The results in the third row show that the lower risk of chronicity among women compared to men contributes much more modestly to the observed sex difference in 12-month prevalence. The results in the fourth row, finally, show that the higher risk of recurrence among women com- pared to men increases across successively older cohorts and has a substantial effect $(46 \%)$ in the oldest cohort. As noted above, Sargeant et al. (1991) documented a similar result in a 1-year prospective study of depression in the ECA study. This consistency of results suggests that greater recurrence among middle-aged women than men plays an important part in explaining the higher prevalence of depression among women in this age range.

\section{Discussion}

We began by documenting increasing rates of lifetime depression in the younger NCS cohorts among both men and women. At age 24 , the oldest age we can compare across all four 10-year birth cohorts in the NCS, the ratio of lifetime prevalence in the youngest versus the oldest cohort is 4.94 among men and 4.93 among women. This trend shows no signs of stabilizing in the youngest cohort. Indeed, the lifetime prevalence at age 24 is more than twice as large in the youngest cohort as in the second youngest cohort (2.34 among men and 2.18 among women). This result is at odds with the evidence presented by Weissman and her colleagues from the ECA and other international epidemiologic surveys that the secular trend for increasing depression in younger cohorts is beginning to stabilize among women. We find no such evidence in the NCS.

Despite the tremendous inter-cohort differences in lifetime depression, the sex ratio of lifetime prevalence in adulthood remains fairly stable over the 40 -year period retrospectively cov-

TABLE 5

Cohort-specific decomposition of the female-male difference in 12-month prevalence of MDE

\begin{tabular}{|c|c|c|c|c|c|c|c|c|}
\hline & \multicolumn{8}{|l|}{ Cohort } \\
\hline & \multicolumn{2}{|c|}{$1966-1975$} & \multicolumn{2}{|c|}{$1956-1965$} & \multicolumn{2}{|c|}{ 1946-1955 } & \multicolumn{2}{|c|}{$1936-1945$} \\
\hline & Metric & Standardized & Metric & Standardized & Metric & Standardized & Metric & Standardized \\
\hline \multicolumn{9}{|l|}{ Incidence } \\
\hline Direct & 0.011 & $(0.206)$ & 0.009 & $(0.243)$ & 0.008 & $(0.170)$ & 0.008 & $(0.111)$ \\
\hline Indirect & 0.065 & $(0.956)$ & 0.030 & $(0.811)$ & 0.042 & $(0.894)$ & 0.035 & $(0.487)$ \\
\hline Chronicity & -0.001 & $(0.000)$ & -0.008 & $(-0.135)$ & -0.014 & $(-0.298)$ & -0.004 & $(-0.056)$ \\
\hline Recurrence & -0.011 & $(-0.162)$ & 0.003 & $(0.081)$ & 0.011 & $(0.234)$ & 0.033 & $(0.458)$ \\
\hline Total & 0.068 & $(1.000)$ & 0.037 & $(1.000)$ & 0.047 & $(1.000)$ & 0.072 & $(1.000)$ \\
\hline
\end{tabular}


ered in the NCS. The estimated value of the female/male lifetime risk ratio for the four NCS cohorts beginning at age 24 averages 1.76 and, in general, does not vary significantly across the four cohorts at any age between 24 and 54 . The stability of the female/male risk ratio means that the factors leading to increased depression have had proportionally similar effects on men and women, an observation that may be useful in searching for plausible explanations for the secular trend in absolute risk.

There is one important way, however, in which the sex difference in lifetime prevalence appears to have changed over this period of time. Consistent with studies of children which have documented significant sex differences in depressive symptoms around the onset of adolescence but not before (Offord et al., 1987; Radloff, 1991), NCS data suggest that the emergence of the sex difference in depression began in early adolescence. However, this was not true in the oldest cohort, among whom the sex difference did not appear until the mid-20s. If this inter-cohort difference in the age when the sex difference first emerges is genuine, it argues against the otherwise plausible interpretation that biological factors associated with puberty are somehow implicated in causing the sex difference to emerge.

A final inter-cohort difference found here concerns 12-month prevalence of depression. We documented that the sex difference in 12-month prevalence is fairly stable across cohorts. The most powerful determinant of this sex difference is lifetime history; that is, people with a prior history of depression, whether men or women, have substantial risks of chronicity and 12-month recurrence. In the NCS, women are more likely than men to be depressed in a given 12-month period because they are much more likely than men to have a prior history. Women also have a higher risk of first onset of depression throughout the 15-54-year age range. However, older women in the NCS are much more likely than older men to have recurrent episodes of depression, a fact which plays an important part in the elevated 12-month depression among women compared to men in the $45-54$ age range. This result replicates a recent prospective analysis of episode resolution in the ECA (Sargeant et al., 1990) and suggests that future research should investigate the determinants of sex differences in recurrence.

The main limitation of this investigation is that the results are based on retrospective data. As noted above, we developed a Life Review Section to address this problem by stimulating complete and accurate recall of lifetime episodes. An indication that this method was at least partly successful is the finding reported in our earlier paper that the ratio of 12-month to lifetime prevalence of MDE decreases with age from a high of $81 \%$ in the $1966-1975$ cohort to a low of $41 \%$ in the 1936-1945 cohort. Although this decrease with age is what one would expect for an episodic early-onset disorder like MDE, it is opposite the pattern found in the ECA study, where the ratio of 12-month prevalence to lifetime prevalence increased with age (Weissman et al., 1991). We interpret the fact that the NCS age trend is more reasonable than the ECA age trend as a sign that the Life Review Section improved accuracy of lifetime recall. It is particularly striking in light of this fact that we still find a pronounced cohort effect in the NCS in a comparison of the youngest cohort with later cohorts. If this cohort effect was largely due to recall failure, we would have expected that our use of the Life Review Section would have led to the effect being less pronounced in the NCS than the ECA. Instead, it is more pronounced in the NCS than the ECA, leading us to believe that the evidence for increasing prevalence of MDE in our most recent cohort is probably genuine rather than due to a methodological artifact.

Despite the use of the Life Review Section, we recognize that the weakest part of the NCS design is the use of retrospective reports and the possibility that some respondents may have forgotten their history of depression or, among those who reported lifetime depression, may have forgotten how early their first episode occurred (Simon and VonKorff, 1992). These recall errors can lead to serious bias in parameter estimates. That episodes of depression are subject to recall bias is consistent with prior retrospective studies demonstrating that a significant reduction in reports of past depressions occurs as the time since their onset increases (Ernst and Angst, 1992; Lewinsohn et al., 1993). Indirect evidence that 
this bias does not account for cohort effects comes from the work of Lewinsohn et al. (1993), who documented that recent birth cohorts have higher rates of depression than older cohorts even after accounting for the length of the recall period. However, the only definitive way to correct this potential problem is to use longitudinal data, cither from a single study carricd out over time (e.g., Ernst and Angst, 1992) or from a series of studies using similar methods that can be spliced together to provide information on trends (e.g., Kessler and McRae, 1981).

A comparison of the NCS with the ECA can be used to provide a limited comparison of the sccond sort which can lct us study 10-ycar differences in recall. When this is done, we find convergence between the two studies in the general pattern of secular trends in depression for both men and women. However, more detailed comparisons are confounded by the fact that the NCS Life Review Section led to much higher rates of lifetime depression than the ECA. This makes it difficult to make fine-grained comparisons between the results of the two studies. For example, it is possible that the later emergence of the sex difference in the oldest NCS cohort might be due to recall bias. We could attempt to test this methodological interpretation by comparing the NCS rcsults for this cohort with results from the ECA. When this is done we find that a significant sex difference in lifetime prevalence appeared in this cohort by age 14 in the ECA data (Wickramaratne et al., 1989). This could suggest that the finding in the NCS that the sex difference did not emerge until age 24 might be due to differential recall bias associated with the 10 year longer recall period. However, our interpretation of this difference is clouded by the fact that the NCS Life Review Section yielded considerably higher estimates of lifetime MDE in this cohort at the age of 14 than in the ECA. Indeed, the absence of an elevated female/male prevalence ratio in the NCS at age 14 is due to the fact that the estimate of lifetime prevalence among men in this cohort at age $14(0.008)$ is over twice as large as the ECA estimate (0.003), while the estimates for women are roughly comparable in the two surveys $(0.008$ in the ECA and 0.007 in the NCS). Based on this confounding of length of the recall period and accuracy of recall, it is impossible to interpret the inter-cohort difference unequivocally by comparing the NCS with the ECA results.

This last finding suggests that the use of the Life Review Section leads to particularly higher reports among men. This is consistent with the results of other investigators who have suggested that men are more likely than women to forget past episodes of depression (Ernst and Angst, 1992) and that recall bias is consequently likely to result in overestimation of the sex difference in depression. It is noteworthy that this sort of bias could explain our finding that the higher 12-month prevalence of MDE among women than men is due largely to the direct and indirect effects of the higher lifetime prevalence among women and not to higher risk of either chronicity or recurrence. Failure to report a lifetime history of depression, leads to overestimation of chronicity and recurrence by underestimating the number of people with a lifetime history who have not had a recent episode. Correcting for this bias might lead to a proportionally greater reduction in the estimated rates of chronicity and recurrence among men than women and to the discovery that women do, in fact, have higher chronicity and recurrence than men. This is an important line of investigation that requires longitudinal data. We plan to pursue an analysis of this issue in future prospective data collection with the NCS sample.

\section{Acknowledgements}

The National Comorbidity Survey (NCS) is a collaborative cpidemiologic investigation of the prevalence, causes, and consequences of psychiatric morbidity and comorbidity in the United States supported by the U.S. Alcohol, Drug Abuse, and Mental Health Administration (Grant 5 R01 MH46376) with supplemental support from the W.T. Grant Foundation (Grant 90135190), Ronald C. Kessler, Principal Investigator. Preparation of this report was also supported by a Research Scientist Development Award to the first author (Grant $1 \mathrm{~K} 01 \mathrm{MH} 00507$ ). Collaborating NCS sites and investigators are: The Addiction Research Foundation (Robin Room), Duke University Medical Center (Dan Blazer, Marvin 
Swartz); Johns Hopkins University (James Anthony, William Eaton, Philip Leaf), the Max Planck Institute of Psychiatry (Hans-Ulrich Wittchen), the Medical College of Virginia (Kenneth Kendler), the University of Michigan (Lloyd Johnston, Ronald Kessler), the National Institute of Mental Health (Darrell Kirsch, Darrel Regier), Ncw York Univcrsity (Patrick Shrout), SUNY Stony Brook (Evelyn Bromet), The University of Toronto (R. Jay Turner), Washington University School of Medicine (Linda Cottler). A complete list of NCS publications can be obtained from the NCS Study Coordinator, Room 1006, Institute for Social Research, the University of Michigan, Box 1248, Ann Arbor, MI 48106-1248.

We would like to thank Evelyn Bromet and William Eaton for helpful comments and Rosetta Myers, Bruce Glasgow, and Sheri Levy for editorial assistance.

\section{References}

Allison, P.D. (1984) Event History Analysis. Sage: Beverly Hills.

American Psychiatric Association. (1987) Diagnostic and Sta tistical Manual of Mental Disorders (3rd Edn., revised). Washington, DC: American Psychiatric Association.

Anthony, J.C., Folstein, M., Romanoski, A.J., VonKorff, M.R., Nestadt, G.R., Chahal, R., Merchant, A., Brown, C.H., Shapiro, S., Kramer, M. and Gruenberg, E.M. (1985) Comparison of the lay Diagnostic Interview Schedule and a standardized psychiatric diagnosis. Experience in Eastern Baltimore. Arch. Gen. Psychiatry 42, 667-675.

Barnett, R.C. and Baruch, G.K. (1987) Social roles, gender and psychological distress. In: R.C. Barnett, L. Biener and G.K. Baruch (Eds.), Gender and Stress. The Free Press: New York, NY, pp. 122-143.

Bebbington, P.E. (1988) The social epidemiology of clinical depression. In: A.S. Henderson and G.D. Burrows, (Eds.), Handbook of Social Psychiatry. Elsevier: Amsterdam, pp. $87-102$.

Burke, K.C., Burke, J.D., Regier, D.A. and Rae, D.A. (1990) Age of onset of selected mental disorders in five community populations. Arch. Gen. Psychiatry 47, 511-518.

Cross-National Collaborative Group. (1992) The changing rate of major depression. Cross-national comparisons. J. Am. Med. Assoc. 268, 3098-3105.

Ernst, C. and Angst, J. (1992) The Zurich study XIl. Sex difference in depression. Evidence from longitudinal epidemiological data. Eur. Arch. Psychiatry Clin. Neurosci. $241,222-230$.

Gove, W.R. and Geerken, M.R. (1977) The effect of children and employment on the mental health of married men and women. Soc. Forces 56, 66-76.
Hagnell, O., Lanke, J., Rorsman, B., and Ojesjo, L. (1982) Are we entering an age of melancholy? Depressive illnesses in a prospective epidemiological study over 25 years: The Lundby Study, Sweden. Psychol. Med. 12, 279 289.

Helzer, J.E., Robins, L.N., McEvoy, L.T. and Spitznagel, E. (1985) A comparison of clinical and diagnostic interview schedule diagnoses. Arch. Gen. Psychiatry 42, 657-666.

Hosmer, D.W. and Lemeshow, S. (1989) Applied Logistic Regression. Wiley\&Son, New York, NY.

Iams, H.M. and Thornton, A. (1975) Decomposition of differences: A cautionary note. Sociol. Methods Res. 3, 341-350.

Janowsky, D.S. and Rausch, J. (1985) Biochemical hypotheses of premenstrual tension syndrome. Psychol. Med. 15, 3-8.

Jenkins, R. (1985) Sex differences in minor psychiatric morbidity. Psychol. Med., Monograph Suppl. 7.

Kessler, R.C., McGonagle, K.A., Swartz, M., Blazer, D.G. and Nelson, C.B. (in press) Sex and depression in the National Comorbidity Survey I: Lifetime prevalence, chronicity and recurrence.

Kessler, R.C., McGonagle, K.A., Zhao, S., Nelson, C.B., Hughes, M., Eshleman, S., Wittchen, H.-U. and Kendler, K.S. (submitted) Lifetime and active prevalence of DSMIII-R psychiatric disorders in the United States: Results from the National Comorbidity Survey.

Kessler, R.C. and McRae, I.A., Ir. (1981) Trends in the relationship between sex and psychological distress: $1957-$ 1976. Am. Sociol. Rev. 46, 443-452.

Kish, L. and Frankel, M.R. (1970) Balanced repeated replications for standard errors. J. Am. Stat. Assoc. 65, 10711094.

Lewinsohn, P.M., Rohde, P., Seeley, J.R., and Fischer, S.A. (1993) Age-cohort changes in the lifetime occurrence of depression and other mental disorders. J. Abnorm. Psychol. 102, 110-120.

Murphy, J.M., Olivier, D.C., Sobol, A.M., Monson, R.R. and Leighton, A.H. (1986) Diagnosis and outcome: depression and anxiety in a general population. Psychol. Med. 16, $117-126$.

Nolen-Hoeksema, S. (1987) Sex differences in unipolar depression: Evidence and theory. Psychol. Bull. 101, 259-282.

Offord, D.R., Boyle, M.H., Szatmari, P. and Rae-Grant, N.I. (1987) Ontario Child Health Study: Il. Six-month prevalence of disorder and rates of service utilization. Arch. Gen. Psychiatry 44, 832-836.

Radloff, L.S. (1991) The use of the Center for Epidemiological Studies Depression Scale in adolescents and young adults. Special Issue: The emergence of depressive symptoms during adolescence. J. Youth Adol. 20, 149-166.

Robins, L.N., Helzer, J.E., Croughan, J.L. and Ratcliff, K.S. (198I) National Institute of Mental Health diagnostic interview schedule: Its history, characteristics and validity. Arch. Gen. Psychiatry 38, 381-389.

Rubinow, D.R. and Roy-Byrne, P. (1984) Premenstrual syndromes: Overview from a methodologic perspective. Am. J. Psychiatry 141, 163-172.

Sargeant, K., Bruce, M.L., Florio, L.P. and Weissman, M.M. (1990) Factors associated with one year outcome of major 
depression in the community. Arch. Gen. Psychiatry 47, 519-526.

Simon, G.E. and VonKorff, M. (1992) Reevaluation of secular trends in depression rates. Am. J. Epidemiol. 135, 14111422.

Spitzer, R.L., Williams, J.B.W., Gibbon, M. and First M.B. (1992) The structured clinical interview for DSM-III-R (SCID). I. History, rationale, and description. Arch. Gen. Psychiatry 49, 624-629.

Srole, L. and Fischer, A.K. (1980) The Midtown Manhattan longitudinal study vs. The mental paradise lost doctrine. Arch. Gen. Psychiatry 37, 209-221.

Weissman, M.M., Bland, R., Joyce, P.R., Newman, S., Wells, J.E. and Wittchen, H-U. (in press) Sex differences in rates of depression: Cross-national perspectives.

Weissman, M.M., Bruce, M.L., Leaf, P.J., Florio, L.P. and Holzer, C., III. (1991) Affective disorders. In: L.N. Robins and D.A. Regier (Eds.), Psychiatric Disorders in America. Free Press: New York, NY.
Weissman, M.M. and Klerman, G.L. (1992) Depression: Current understanding and changing trends. Annu. Rev. Public Health 13, 319-339.

Wickramaratne, P.J., Weissman, M.M., Leaf, P.J. and Holford, T.R. (1989) Age, period and cohort effects on the risk of major depression: results from five United States communities. J. Clin. Epidemiol. 42, 333-343.

Wilhelm, K. and Parker, G. (1989) Is sex necessarily a risk factor to depression? Psychol. Med. 19, 401-413.

Winsborough, H.H. and Dickinson, P. (1971) Components of negro-white income differences. Proceedings of the Social Statistics Section. Washington: American Statistical Association.

Woodruff, R.S. and Causey, B.D. (1976) Computerized method for approximating the variance of a complicated estimate. J. Am. Stat. Assoc. 71, 315-321.

World Health Organization. (1990) Composite International Diagnustic Interview, (CIDI, Version 1.0). World Health Organization: Geneva. 